\title{
THE IMPACT OF FAMILY EDUCATIONAL STRATEGIES ON ABNORMAL PERSONALITY DEVELOPMENT
}

\author{
Doina USACI, Ph.D., \\ University Transilvania of Brasov \\ doina.usaci@gmail.com
}

\begin{abstract}
This paper presents the most relevant parentig strategies and their impact on personality development. Abnormal personality follows the same type of evolution as the normal personality, in terms of the nature of the determinants factors of development. The quality of these factors and their actions makes the difference. We have presented some factors: (1) family educational practices, (2) parental education strategies (3) dimensions of parental behavior (4) alienated family behaviors and their impact on the the development of abnormal personality. All these inadequate educational strategies will disrupt the normal process of personality development, alter the child's self-image, his cognitive schemas, relational modalities, and increase the risk of building a rigid, defensive personality. Early identification of such risks and intervention on the child and family may have real prophylactic and curative effects.
\end{abstract}

Keyword:Personality, abnormal personality, parental education strategies, dimensions of parental behavior, alienated family behaviors

\section{Introduction}

Personality, also called "the keystone of psychology and psychopathology" (Ionescu, 1997) is a concept of maximum generality that knows dozens of definitions and hundreds of meanings. In this paper, we consider the personality as a stable, but flexible pattern of beliefs, ideas, feelings, attitudes and behaviors that express the psychological identity and uniqueness of a person in relation to the existential context in which she evolve, and with the concrete life events. Personality exhibits o great variability of manifestations. But, despite its diversity of expression in different people, on a more detailed analysis, we can see that personality presents an ensemble of specific characteristics such as constancy and stability, organization and hierarchy, uniqueness and originality as well as 
the predictive potential of the behavior. In certain situations, however, the traits are persistently, durably and rigidly anchored in the extreme area of a psychological dimension and express themselves with extreme intensity and inflexibility in relation to situational variability. This maladaptive behavior differs significantly from that expected by the culture in which the individual evolves and can create family and social dysfunctions, which leads to significant distress for that person and those around him. In the extreme, these people can be diagnosed as having a personality disorder. (Seligman et al., 2001, p.371)

\section{Abnormal personality development}

We can represent Abnormal Personality as a "non-Euclidean" building, that is placed on an unstable foundation, which puts it at risk of a possible collapse at the slightest shock. On this more or less unstable foundation, the building rises further, in the absence of an initial project, following spontaneous decisions and using improvised building materials.

A building whose structure is affected, which lacks the harmony between elements and the functionality is what results from this demarche. In this non-Euclidean house, the host itself feels pressed, without psychological comfort and often terrified by the possibility of collapse. Those close to the house feel the discomfort created by the tightened angles, inclined planes and dark corners. Those passing by the front of the house are amazed by these strange forms and often cross to the other sidewalk, fearing not to be hurt by a possible downfall.

„A personality disorder is an enduring pattern of inner experience and behavior that deviates markedly from the expectations of the individual's culture, is pervasive and inflexible, has an onset in adolescence or early adulthood, is stable over time, and leads to distress or impairment." (DSM-5, p. 645) Personality is abnormal, either in terms of the quality and expression of its behaviour, or in terms of its overall appearance. For this reason, the patient suffers or causes others to suffer, generating adverse effects on the individual and society.

The DSM-5 includes ten personality disorders whose portrait we will present in the follow.

Schizoid Apathetic, unconcerned, insensitive distant, solitary. He has

personality no desires, no need of human attachment. Minimum degree of awareness of one's own or others' feelings. Few impulses or ambitions, if any.

Paranoid Defensive, distrustful and suspicious. Hypervigilant to the personality motives of others to undermine or hurt them. He's always looking for evidence to confirm the hidden schemas. He feels persecuted 
Schizotypal Eccentric, self-alienated, bizarre, absent. Specific manners and personality behaviors. He thinks he can read the others' thoughts. Strange dreams and beliefs. Instable boundaries between reality and fantasy

Histrionic Dramatic, seductive, superficial, seeking of stimuli. Excessive personality reaction to minor events. His exhibitionism is manifested as a means of ensuring attention and favors. He sees himself as attractive and charming.

Narcissic Egoist, arrogant, grandiose. Fantasies about his own success, personality beauty or achievements. He sees himself as admirable and superior and therefore considers himself entitled to special treatment.

Borderline Unpredictable, manipulative, unstable. Fear of abandonment personality and isolation. They experience fast fluctuations. Rapid changes between love and hate. He sees himself and the others as being all good or bad.

Dissocial Impulsive, irresponsible, deviant, undisciplined. He respect personality social obligations only when that serving them. Lack of respect for social habits, rules and standards. He sees himself as free and independent.

Dependent Helpless, incompetent, obedient, immature. Do not assume personality adult responsibilities. He sees himself as weak or fragile. He constantly search reassurance from strong figures.

Obsessive Conscientious, respectful, rigid. Maintains a lifestyle compussive respecting the rules. He adheres closely to social conventions. personality He respects the regulations and hierarchies. He sees himself as devoted, trustworthy, efficient, and productive

Avoidant Self-conscious, embarrassed, impatient. Tense in social personality situations because of fear of rejection. Constantly tormented by performance anxiety. He sees himself as inept, inferior, or unattractive. He feels alone and empty inside.

Tabel 1. Personality disorders (adapted from Milon, 2004)

\section{Abnormal personality development}

Personality development or personogenesis is a progressive process of building operational operational, instrumental and regulatory structures which will allow to a good adaptation in a social context, an optimal use of individual resources and a permanent self-actualization.

Abnormal personality follows the same type of evolution as the normal personality, in terms of the nature of the determinants factors of development. The quality of these factors and their actions makes the difference. In order to distinguish between normal and abnormal personality 
development, Millon (2004) proposes „developmental pathogenesis”, a concept closer to a dimensional approach and having deeper roots in the psychology of personality. In the pathogenesis of personality, Millon differentiates predisposing factors and precipitating factors. Predisposing factors, such as heredity, socioeconomic status, family atmosphere, and habits learned in response to early traumatic experiences serve as a foundation for the development of a personality disorder. Precipitating factors (eg. the death of a parent) refer to clearly demarcated events which evoke or trigger the expression of allready existing, but latent and hidden, dispositional factors.

Lăzărescu \& Nireştean (2007, p. 117) introduce a very relevant concept to understand the processuality of the development of personality disorders, ,pathological personogenesis", which includes the action of hereditary / constitutional factors, childhood experiences and peculiarities, interpersonal relationships and social factors.

The family is the main socializing agent that will accompany the development of the child throughout it. The quality of the organization and functioning of the family depends fundamentally on how the dynamic process of personogenesis will take place. We will briefly present some socialization theories that highlight the role of the family in the normal development of personality.

The Social Mold Model, Hartup (1978), specifically developed in order to explain the deviant behavior, compares family's socialization processes with a mold in which the child is placed, its behavior being the result of the action of various parental, positive or negative educational strategies. The most important educational strategies are the parental support and the parental control. (Huh et al. 2006) Significant parental support and monitoring help child development, encourage initiatives and autonomy, stimulate information processing and decision-making and thus reduce the incidence of deviant and antisocial behaviors (Durbin et al., 1993

Reciprocal Effects Model suggests the reciprocity between parental behavior and child behavior. Parental strategies will influence the behavior of the child, but in turn, the child's behavior will influence the parent's reaction. An irritable child, with a high level of reactivity and a constantly negative emotional state, will more likely generate aversive behaviors from parents. Equally, a harsh discipline from the parent will produce different responses to children with different temperaments.

Coercion Theory (Patterson, 1992, 2002, Dishion \& Patterson, 1997) is a prototypical example of reciprocal influences between parents and children: Inappropriate or antisocial behavior of a child provokes aversive reactions from parents; these aversive reactions, in turn, escalate aggressive behavior of the child. 
The Bronfenbrenner's ecological model analyzes five socially organized subsystems that support and guide the child's development process. The family, which in the first years of life is the most important part of the care environment, is the child's microsystem. Parents or family characteristics, educational strategies and practices can contribute to the development of a personality disorders.

\section{Inadequate educational strategies and the impact on personality development}

Family education proves to be one of the most important factors influencing the development of both normal and abnormal personality.

The constellation of family education is extremely complex. We will briefly develop only a few aspects: (1) family educational practices, (2) parental education strategies (3) dimensions of parental behavior (4) alienated family behaviors and their impact on the the development of abnormal personality.

Parental educational practices are concrete behaviors, which are manifested in specific situational contexts. Stormshak et al (2000) analyzes five parental practices associated with the development of behavioral problems: (a) punitive discipline (screaming, teasing, threats),(b) lack of consistency of parental behavior, (c) lack of warmth and positive involvement, (d) physical aggression (hitting, beating), (e) corporal punishment.

Educational strategies include several congruent parental practices and are used in relation to a child's specific behavior (eg. effective discipline strategies based on explanation, communication, appropriate punishment in relation to the guilt, negotiation and rule setting, behavioral evaluation etc. versus harsh disciplining strategies, based on reproaches, quarrels, admonishment, violence). Depending on their positive or negative character, on their nature and quality, certain educational strategies generate appropriate or inappropriate behaviors of the child, being integrated into the personality structure if they are constantly manifested. Low affection, lack of parental love, reduced time spent with the child, poor communication, inappropriate childcare, low aspirations for the child have been associated with the characteristic symptoms of conduct disorders, such as feelings of insecurity, emotional regulation difficulties, the child's anger, stubbornness and non-compliance. The absence of positive reinforcements, an invalidating developmental context, where the child's feelings are denied generates the internalizing disorders, which involve social withdrawal, and a high level of anxiety (Cole \& Rehm, 1986). The avoidant personality or borderline personality develops in this "fertile" environment. 
Parenting dimensions include parenting practices, placed on a continuum, which express a certain behavior. Support and control are the two dimensions widely used to assess the quality of parental behavior. (Moitra \& Mukherjee, 2010)

Parental support (warmth, affection and acceptance versus hostility, neglect and rejection) defines how the parent responds to the needs of the child and supports his development.

Parental control is the second dimension of parenting. The literature contains many attempts to conceptualize control, but data are inconsistent and equivocal (Barber 2006). Amato (1990) has defined ,parental control”, as beeing ,the degree of parental monitoring of children, the decisions which the parents make regarding children's activities and friends, and the rules which the parents set for their children". (apud Suchman, 2077)

Barber (1996) has differentiate the psychological control from the behavioral control.

Psychological control is defined as "socializing pressure that does not respond to the emotional and psychological needs of the child, but, on the contrary, it inhibits the expression of independence and autonomy" (p. 3299). More specifically, psychological control refers to "parental behaviors that are intrusive and are based on the manipulation of children's thoughts and feelings and their attachment to parents" (Barber \& Harmon, 2002, p. 15)

Psychological control includes a variety of maladaptive parental strategies, such as: (1) Inducing the feeling of culpability - the manipulation of feelings of guilt to put pressure on children in order to comply in accord with parents' requirements; ("That's why your mother is sick, because you never listen to her.") (2) Conditional love or withdrawal of love manipulation of the attention, concern and affection in order to the child respond to certain requirements and reach parental standards; ("If you do not learn very well, Mommy will not love you anymore.") (3) Inducing anxiety to make children feel inferior, to make them feel shame, to induce a sense of incompetence in order to compel children to follow the parents' demands; ("The professor told me that, instead to draw, you play with another child, nothing good will happen to you."); (4) Invalidating the child's perspective the obstruction of the spontaneous expression of thoughts and feelings of children, the denial of their ideas, emotions, and experiences. ("Well, it hurts your stomach! You say this just to avoid making lessons.")

Behavioral control refers to the parental attempts to regulate and structure the behavior of the child (activities and participation in joint actions with colleagues), by communicating behavioral rules and monitoring the proper child behavior (Dishion \& McMahon, 1998)

Psychological control has detrimental effects on children functioning, on their academic performances, and on their relationships with the family 
and peers. Psychological control disturbs the positive sense of self (Barber, 2014), increases the risks of internalization disorders, affects the need of autonomy, children being forced to act, feel, or think exclusively in accord with their parents requirements and expectations. While behavioral control provides children with a clear set of guidelines for proper behavior, by contrast, psychological control interferes with normal personality development, disturbing the needs for autonomy, competence and relatedness.

Alienated parenting strategies are complex behaviors, with a strong negative educational impact, which cause severe harm to the child, in the process of personality development. These alienated behaviors occur, either in the context of a parent's personality disorder or other psychiatric disorder, or in certain existential contexts that present a severe psychological risk to a vulnerable parent, such as divorce. The alienated parental behaviors are parentification, adultification and infantilisation.

Parentification means to reverse the roles between the parent and the child, especially in the context of divorce. The child's needs are sacrificed to meet the emotional needs of one or other of the parents or of other family members. Parentification is a form of child abuse. In the context of divorce, the parentified child is called to comfort his parents about adult distress, instead of living their own suffering"(Peris et al., 2008, p.634).

Adultification supposes that a child assume some roles that traditionally belong to the adult. In the context of divorce, the adultificated child becomes friend and confidant of the parent with whom he usually remains, sharing his physical and emotional responsibilities with him.

Infantilization is due to, either the inability of the parent to accept the growth and maturation of his or her own child, or the fearing of the parent to be left by the child who was fulfilled all his emotional needs. Consequently, the parent prevents the child from making friends, forbids him to participate in age-specific activities, and makes him guilty of any attempt to assert his independence. In the extreme, the parent will induce and maintain the idea that the child is very ill and needs permanent care of its part.

\section{Conclusion}

In conclusion, all these inadequate educational strategies will disrupt the normal process of personality development, alter the child's self-image, his cognitive schemas, relational modalities, and increase the risk of building a rigid, defensive personality.

Early identification of such risks and intervention on the child and family may have real prophylactic and curative effects. 


\section{References}

Amato P. (1990). Dimensions of the family environment as perceived by children: A multidimensional scaling study. Journal of Marriage and the Family. no52, pgs. 613-620.

Barber, B.K. (1996). Parental Psychological Control: Revisiting a Neglected Construct. Child Development, No. 67, pgs. 3296-3319.

Barber, B. K., \& Harmon, E. L. (2002). Violating the self: Parental psychological control of children and adolescents. In B. K. Barber (Ed.), Intrusive parenting: How psychological control affects children and adolescents (pp. 15-52). Washington, DC: APA.

Brofenbrenner, U. (1994). Ecological models of human development, in International Encyclopedia of Education, vol.3, 2nd. Ed. Oxford Elsevier

Cowan CP, Cowan PA. (2000). When partners become parents: The big life change for couples. Mahwah, NJ: Lawrence Erlbaum Associates

Dishion, T. J., \& McMahon, R. J. (1998). Parental monitoring and the prevention of child and adolescent problem behavior: A conceptual and empirical formulation. Clinical Child and Family Psychology Review, 1, 6175.

Durbin, D. L., Darling, N., Steinberg, L. \& Brown, B. B. (1993). Parenting style and peer group membership among European-American adolescents. Journal of Research on Adolescence, 3(1), 87-100.

Ionescu, Ghe. (1997) Tulburările personalitatii, Ed. Asklepios, Bucuresti

Kumar, P., Tiwari, S.C (2000). Family and Psychopathology: An Overview, Series-1: Children and Adults, Delhi Psychiatry Journal, Vol. 11, No.2, Posted online Oct.2008, Retrieved on August 6, 2014, from http://medind.nic.in/daa/t08/i2/daat08i2p140.pdf

Huh, D., Tristan, J., Wade, E., Stice, E. (2006). Does Problem Behavior Elicit Poor Parenting?: A Prospective Study of Adolescent Girls, Journal of Adolescent Research, 21, 185-204. doi: 10.1177/0743558405285462

Millon, T. et al. (2004). Personality disorders in modern life, John Wiley \& Sons, Inc., Hoboken, New Jersey.

Lazărescu M, Niresteanu, A., (1997). Tulburările de personalitate, Ed. Polirom, Iași

Peris, T. S., \& Emery, R. E. (2005). Redefining the parent-child relationship following divorce: Examining the risk for boundary dissolution. Journal of Emotional Abuse, 5(4), 169-189.

Porter, L. (2008). Young Children behavior; Practical Approaches for Caregivers and Teachers, MacLennan \& Petty, Elsevier Australia, p.4

Garber B.D. (2011). Parental alienation and the dynamics of the enmeshed parent-child dyad: adultification, parentification, and infantilization, Family Court Review, vol. 49, no. 2, 322-335 
Soenens, B., Vansteenkiste,R. (2010). A theoretical upgrade of the concept of parental psychological control: Proposing new insights on the basis of selfdetermination theory, Developmental Review, 30, 74-99

Teicher, Samson, Polcari \& McGreenery, (2006). Sticks, stones, and hurtful words: relative effects of various forms of childhood maltreatment, American Journal of Psychiatry, 163(6), pgs. 993-1000.

Usaci, D. (2004). Psihopatologie si psihiatrie, Ed. Universității Transilvania, Brasov 